\title{
ATRIBUTOS DA PRESTAÇÃO DE SERVIÇOS PARA OPERAÇÕES LOGÍSTICAS DE COMMODITIES AGRÍCOLAS NA VISÃO DOS EMBARCADORES
}

\author{
Ari Antonio Scherer ${ }^{1}$ \\ Ricardo Silveira Martins ${ }^{2}$
}

Resumo - O objetivo deste estudo foi identificar os atributos valorizados na contratação de operações logísticas pelos embarcadores na tomada de decisões no mercado de commodities agrícolas, com interesse específico na identificação dos principais critérios para contratação e avaliação de um operador logístico. A utilização de operadores logísticos pode ser entendida a partir do aperto nas margens de operação, que tem forçado as empresas a tomarem decisões sobre a viabilidade de otimizarem todas as operações ou buscarem em prestadores de serviço a solução otimizadora. As informações foram obtidas de questionários encaminhados aos responsáveis pela comercialização de empresas que comercializam um volume significativo de grãos. Como síntese dos resultados, pôde-se constatar que o transporte é a principal e, às vezes, única dentro da visão logística do setor. Mesmo que não-sistemática, avaliação da qualidade do serviço prestado é feita pelo embarcador. A frequiência das operações faz com que seja facilitada a tarefa de avaliação do desempenho dos prestadores de serviço. Conforme avaliação dos embarcadores, os itens mais importantes no serviço prestado são, na seqüência, flexibilidade, reação às reclamações e o serviço de transporte propriamente dito. Em suma, pode-se concluir que existe rigidez na gestão logística da comercialização de commodities agrícolas, e os embarcadores, estrategicamente ou pela própria dinâmica do mercado, tendem a "commoditizar" os serviços logísticos, não avaliando o potencial de ganho de terceirização de operações além do transporte, o que faz com que, para esses negócios, transporte e logística sejam sinônimos.

Palavras-chave: Logística agroindustrial, operador logístico, comercialização.

Economista, Cx. Postal 520 85.900-970 Toledo - PR. E-mail: arischerer@ibest.com.br.

${ }^{2}$ Professor Adjunto da Unioeste/Campus de Toledo e líder do TRANSLOG - Grupo de Pesquisas em Transportes e Logística Agroindustrial Cx. Postal 520 85.900-970 Toledo - PR. E-mail: ricleimartins@uol.com.br.

Recebido em 11/12/2003 Aceito em 29/12/2003 


\section{Introdução}

As últimas décadas foram marcadas por mudanças conceituais e estruturais que ocorreram no ambiente empresarial. Muitos dos conceitos de produção enxuta surgiram em contraponto a práticas gerenciais que valorizavam os altos níveis de estoque em toda a cadeia. Outro exemplo é a progressiva diversificação dos produtos manufaturados, que, conforme o aumento do grau de exigência ou a expectativa do cliente final, obrigava a empresa a trabalhar de forma mais flexível, inclusive para suportar a fabricação de diferentes modelos e diminuir seus níveis de estoque ao longo da cadeia.

Outra característica marcante nas grandes empresas, na década de 70, foi a busca pelo domínio de todas as atividades (industriais ou não) que faziam parte dos processos produtivos de suas manufaturas. Essas atividades extrapolavam o âmbito dos processos industriais e de montagem para atividades administrativas ou de apoio. Era comum, naqueles momentos, as empresas terem em seus quadros funcionários designados para funções de limpeza, vigilância, transporte, cozinha, saúde, etc. Uma grande empresa, muitas vezes, era definida não apenas pelo seu faturamento, mas pelo porte de suas instalações e pelo número de funcionários que ali trabalhavam.

Sob um novo cenário de globalização de mercados, aumento da competição interna e externa advinda dessa globalização e aumento do custo da mão-de-obra em todo o mundo, as empresas (principalmente as industriais) tiveram que repensar suas estruturas e filosofias de trabalho. Uma mudança agressiva começou a surgir como reflexo desse novo cenário competitivo, sendo que as relações fornecedor-cliente começaram a se estreitar e ser administradas de forma estratégica, além de a automação comercial abrir novas fronteiras aos grandes varejistas e prestadores de serviços. Essa etapa do processo evolutivo da logística foi definida, por Novaes (2001, p. 41), como Integração Flexível da Cadeia. A partir da década de 90 até os dias de hoje, aprimora-se progressivamente a relação entre clientes - fornecedores, sendo que 
a concepção de parceria extrapola as meras relações comerciais de prestação de serviço para a definição de estratégias e diretrizes conjuntas. Mas, além da melhoria da relação com o fornecedor (comaker), que, historicamente, sempre foi um provedor de matériaprima ou de partes da manufatura produzida pelo cliente, uma tendência observada nesta década foi a de muitas empresas estarem buscando a terceirização de "processos ou atividades não-básicas", que, até esse momento, eram desenvolvidas dentro de suas instalações (Dornier $e t$ al., 2000). A partir da definição de suas core competences, principais competências, definem-se quais são os processos básicos da empresa e os não-básicos, que, segundo análise da direção desta empresa, podem vir a serem realizados por outro prestador de serviços ou indústria.

Atualmente, tanto os clientes como os próprios fornecedores já se habituaram à figura da empresa "terceirizada", principalmente no setor de prestação de serviços. Ao enxugar suas estruturas organizacionais, parte das operações de assistência técnica e manutenção dos grandes fabricantes de eletroeletrônicos, por exemplo, é feita por pequenas empresas terceirizadas que realizam essas atividades. Até mesmo a ligação telefônica feita por um cliente descontente, que comprou um aparelho e não conseguiu realizar as funções desejadas, tem grande probabilidade de ser atendida por um funcionário de um prestadora de serviço que lida com as comunicações do pós-venda com os clientes, call center, que terceirizou seu help desk.

Ao aproximar os interesses dessa estratégia de terceirização do ambiente logístico, como fator de aumento da competitividade empresarial, podese observar que, além das atividades citadas anteriormente, a armazenagem, a estocagem e o transporte também são comumentemente terceirizados nos dias de hoje. Isso se dá pelo processo natural das empresas de centralizam seus esforços nos processos ou atividades que são mais competentes, dado o alto nível de desenvolvimento e dada a qualidade dos serviços oferecidos por prestadores de serviço logísticos ou operadores logísticos, que estão prontos para atender a uma gama muito grande de potenciais empresas terceirizadoras (dos mais diversos 
setores e perfis), e, dessa forma, dar mais agilidade aos processos que anteriormente eram considerados gargalos na cadeia de suprimentos dos seus clientes.

Os serviços logísticos são prestados pelo operador logístico, um conceito que é marcado pela diversidade de compreensões. Na literatura, Novaes (2001) obteve uma definição de operador logístico como sendo um agente capacitado a oferecer a seus clientes o atendimento de todas ou de quase todas as necessidades referentes à cadeia de logística integrada, de forma personalizada. Essa definição enfatiza a personalização do serviço, em que a contratação de um operador logístico implica a obtenção da melhor qualidade dos serviços, sem que a empresa contratante perca o foco de seus negócios.

Já de acordo com Robles (2001), podem-se acrescentar outras funções ao operador logístico. Estudos deste autor evidenciam que, na indústria automotiva, os operadores assumem funções de submontagens, tarefas relacionadas com projetos e domínio de tecnologias, responsáveis pelo desenho e pela análise de soluções logísticas.

Novaes (2001) apresentou uma definição do operador logístico, de maneira mais convencional, destacando-se que, para existir uma separação entre os dois agentes, é necessário que as atividades logísticas sejam realizadas de forma integrada e coordenadas, sendo esta a diferença básica entre o operador logístico e um simples prestador de serviços.

Assim, um operador logístico deverá oferecer seu conjunto de serviços, de maneira coordenada e integrada, fazendo as adaptações necessárias para que as necessidades do cliente e suas características não sejam esquecidas, agregando, assim, maior eficiência à cadeia de suprimentos.

Novaes (2001) fez ainda referência ao operador logístico integrado, que tem o sentido de alocar ao operador logístico a prática de serviços administrativos e físicos operacionais ao mesmo tempo, trazendo a empresa mais próxima ao operador logístico. 
O mercado de prestação de serviços logísticos vem crescendo muito rapidamente em todo o mundo e, por consequiência, também no Brasil. São várias as evidências deste fenômeno. Boyson et al. (1999) mostraram que, na indústria química norte-americana, o número médio de atividades logísticas terceirizadas, por empresa, cresceu de 1,5 para 5,5, no período de 1989 a 1995, o que indica forte tendência de aumento do escopo de serviços logísticos terceirizados. Na mesma época, uma reportagem da revista Fortune indicava que $60 \%$ das 500 maiores empresas por ela listadas terceirizavam pelo menos uma das atividades que compõem seu processo logístico, uma evidência do nível de difusão da prática de terceirização logística.

No Brasil, apesar de o processo de terceirização das atividades logísticas ainda ser relativamente recente e de não existirem estatísticas confiáveis, o potencial de mercado parece elevado. Estima-se que somente os gastos com transportes no país sejam equivalentes a $10 \%$ do PIB, o que corresponderia a cerca de US\$ 60 bilhões. Os grandes prestadores de serviços logísticos internacionais parecem ter percebido este potencial. A partir de 1997, empresas como Ryder, Penske Logistics - em joint venture com a Cotia Trading, Mc Lane (do grupo Wall Mart) -, Mark VII, Emery Worldwide, Hellmann Logistics, Danzas e Mosolf passaram a desembarcar no país, juntando-se a um crescente número de empresas brasileiras, como Columbia, Cometa, Metropolitan, Delara, Marbo, Mercúrio, Hércules e Delta, que já vinham tendo crescimento substancial neste mercado.

Como exemplo, pode-se citar a contratação das operações logísticas realizadas pela ALL - América Latina Logística, que faz toda a logística da SLC Alimentos, terceira colocada no ranking nacional de arroz, responsável pelo fluxo de arroz desde beneficiadoras do Rio Grande do Sul até o mercado consumidor de São Paulo, Rio de Janeiro e Minas Gerais, num volume que representa $80 \%$ da produção da empresa, cliente desde $1^{\circ}$ de agosto de 2002 . 
Embora bastante recente, a indústria de Prestadores de Serviços Logísticos (PSL) vem evoluindo rapidamente no Brasil. Uma das conseqüências dessa evolução tem sido o surgimento de vários formatos de atuação, que tem levado a uma dificuldade de categorização dos prestadores de serviços logísticos. Pouco também se conhece sobre as principais barreiras e oportunidades para atuação dessas empresas no Brasil.

No Brasil, recente estudo sobre PSLs, realizado conjuntamente pela Associação Brasileira de Logística, Fundação Getúlio Vargas e Associação Brasileira de Movimentação e Logística, define operador logístico como o fornecedor de serviços logísticos especializado em gerenciar e executar todas ou parte das atividades logísticas nas várias fases da cadeia de abastecimento dos seus clientes e que tenha competência para, no mínimo, prestar simultaneamente serviços nas três atividades básicas de controle de estoques, armazenagem e gestão de transportes. Os demais serviços que, porventura, são oferecidos funcionam como diferenciais de cada operador. Esta definição é bastante semelhante àquela utilizada para os $3 P L s$, excetuando-se o fato de que esta última menciona a integração das atividades como elemento presente no seu conceito.

As iniciativas de terceirização das atividades da logística revelam a necessidade, principalmente das empresas dos mais diversos setores que atuam em mercados globalizados, de agregar maior valor aos seus produtos ou serviços, sem reverter, necessariamente, essas vantagens em aumento de custo e, consequientemente, de preço. Segundo Csillag (1995, p. 62), quanto maior é o valor de um item sobre outro que sirva para a mesma finalidade, maior será a probabilidade de vencer a concorrência. Já Razzolini F. (2000, p. 10) acrescentou que, a partir de um posicionamento logístico estratégico, ao fornecer um valor superior aos seus clientes, satisfazendo suas necessidades elou expectativas, com certeza estarão fidelizando seus clientes e, com isso, gerando relações duradouras e lucrativas para ambas as partes. Dessa forma, os setores característicos de mercados internacionalizados, em razão da profissionalização de suas atividades, têm tido considerável desenvolvimento econômico nos últimos anos. Um destes foi o setor 
agropecuário, mais precisamente o de grãos, que sentiu no aumento de suas fronteiras de exportação e na entrada de seus produtos em mercados estrangeiros o forte reflexo dos investimentos realizados em desenvolvimento de sementes híbridas para o plantio em regiões com diferentes características de solo, água, temperatura e umidade, dos investimentos realizados em processos de reutilização e tratamento de água, de manejo integrado de pragas, da utilização de rodízio entre culturas e, entre outras coisas, da melhoria na gestão das propriedades produtoras e cooperativas agrícolas.

Assim, o objetivo desta pesquisa foi identificar os atributos valorizados na contratação de operações logísticas pelos agentes na tomada de decisões no mercado de commodities agrícolas, com interesse específico na avaliação dos principais critérios para contratação e avaliação de um operador logístico, assim como verificar a existência de um padrão adotado pelos contratantes nesta avaliação.

\section{Marco teórico-conceitual}

Devido à perspectiva atual de as atividades empresariais desenvolverem-se em mercados abertos e globalizados, sem barreiras ou restrições comerciais, novas formas de gestão tiveram de ser criadas, para ajustarse às características desse novo momento. Muito se escutou, na última década, sobre as novas formas de gerência, em que se deslocou o foco da produção para outras atividades, tendo as atividades comerciais, de marketing e de qualidade ganhado notável destaque pela importância dada aos seus resultados como forma de agregar valor aos produtos, processos e serviços envolvidos.

Vale recordar que, há algumas décadas, alguns fatores que levavam uma empresa a destacar-se no seu setor poderiam ser seus altos níveis de estoque, grande estrutura física e alta capacidade produtiva instalada, da mesma forma que, muitas vezes, as empresas buscavam destacar-se competitivamente, diluindo custos com a economia de escala. 
Porém, como reflexo da facilidade ao acesso a novas tecnologias, dada a melhoria das formas de comunicação e dada a popularização do acesso à informação, grande parte das empresas chegou a um mesmo patamar tecnológico nos seus negócios, principalmente no que se refere à automatização e controle de processos, no controle de recursos humanos, de fornecedores, de vendas, de armazém, de estoques, de qualidade, e à melhoria da eficiência interna como resultado disso.

Considerando-se que, até certo ponto, as empresas trabalham sob um mesmo nível de desempenho, e levando em conta que grande parte dos processos internos estava próxima da otimização, a competição entre elas acabou sendo voltada aos processos não-otimizados ou vagamente gerenciados até aquele momento.

Justamente nesse momento, surge a possibilidade de aumentar o valor agregado dos produtos, processos ou serviços, desenvolvendo melhor gestão das atividades logísticas envolvidas, sendo que, antes disso, considerava-se a logística meramente operações de transporte realizadas pela empresa (interna e externamente), e, por não ter nenhum caráter estratégico, não necessitava de uma abordagem estratégica própria.

Uma grande mudança estrutural gerada pelo processo de internacionalização de mercados foi justamente elevar a logística a um primeiro plano estratégico, quando se estudam os mecanismos para alavancar a vantagem competitiva nas empresas. Ao tratar deste assunto, Alves (2000, p. 16) recordou que, até recentemente, a visão estratégica das empresas, quanto ao comércio internacional, era dirigida quase que exclusivamente aos aspectos mercadológicos, enquanto às atividades de logística cabia contribuir operacionalmente para o sucesso da empresa.

O fato é que a incessante otimização da manufatura nas últimas duas décadas e a aplicação de novas técnicas gerenciais, tais como just in time (JIT), gestão da qualidade total (TQM - total quality management) e sistemas flexíveis de manufatura (FMS - flexible manufacturing systems), melhoraram significativamente o desempenho empresarial, 
segundo Dornier et al. (2000, p. 81). Entretanto, acabaram gerando aumento no volume e na complexidade das atividades logísticas, principalmente pelas características dos novos mercados globalizados, onde os produtos são movidos de maior número de origens para maior número de destinos, de forma mais rápida e eficiente.

A globalização que impulsionou grande número de empresas atuantes em mercados internacionais significa, entre outras coisas, comprar e vender em diversos lugares ao redor do mundo. Os impactos desse fenômeno no ambiente empresarial foram muitos, entre eles, o aumento do número de clientes e de pontos de venda, o crescimento do número de fornecedores e distribuidores e o aumento das distâncias a serem percorridas. Observam-se, também, maior desenvolvimento da intermodalidade e maior preocupação nas empresas em atender aos aspectos fiscais, legais e culturais e à expectativa dos clientes dos mercados dessas novas fronteiras. Em suma, gerou-se uma complexidade das atividades logísticas.

Aos poucos, foi-se compreendendo que no novo ambiente empresarial competitivo, chamado por Kaplan e Norton (1997) de a Era da Informação, uma visão pautada unicamente nos aspectos mercadológicos não era suficiente.

Nesse ambiente, ainda segundo eles, tanto para as organizações do setor de produção quanto para as do setor de serviços, são necessárias novas capacidades para assegurar o sucesso competitivo.

De acordo com essas considerações, Colli (2001, p. 10) apontou que $o$ gerenciamento logístico surge no cenário corporativo como a alavanca capaz de fornecer às empresas as capacidades diferenciadoras necessárias, ou, em outras palavras, vantagens competitivas, que certamente as colocarão em destaque no cenário mercadológico.

Claramente, percebe-se que, nos mais variados setores industriais ou não, as funções relacionadas com os processos logísticos atualmente 
são consideradas de alto poder estratégico, com a capacidade de definir o sucesso mercadológico de um produto/serviço, principalmente, pelo desempenho apresentado em custos, capacidade (produtividade), tempo, qualidade e nível de serviço.

Seguindo no tema da busca de competitividade por parte das empresas, Porter (1991) sugeriu quatro fontes para o alcance da vantagem competitiva global, quais sejam, vantagem comparativa convencional, economias de escala, vantagens decorrentes da diferenciação do produto e o caráter de bem público da tecnologia e das informações de mercado. Segundo ele, para demonstrar a força da utilização da logística de forma estratégica, visando ao aumento da capacidade competitiva das organizações, propõe-se um item de estudo chamado Economias Logísticas de Escala dentro da fonte Economias de Escala.

Neste item, ele fortalece a idéia de que sistemas logísticos internacionais que envolvem inerentemente custos fixos, que podem ser divididos por meio de um atendimento a vários mercados nacionais, sempre trarão vantagens competitivas aos concorrentes globais envolvidos e que adotam semelhante solução. Assim, as empresas que gerenciam suas atividades logísticas de forma estratégica, utilizando as estruturas internacionais desenvolvidas e oferecidas de forma indistinta a todas as empresas de todos os setores para otimização de suas atividades, estarão um passo a frente daquelas que tratam suas questões logísticas meramente como transporte de matéria-prima e de produto acabado. A concorrência global também pode permitir que economias de escala sejam obtidas na logística, em decorrência da possibilidade do uso de sistemas mais especializados, como, por exemplo, no setor de transporte de cargas agrícolas de grãos a granel e no uso de vagões ferroviários e navios cargueiros especiais.

Nesse atual cenário globalizado, as empresas que atuam em um mesmo mercado internacional costumam apresentar um estágio tecnológico muito uniforme. Além disso, utilizam as mais modernas formas de gestão para controlar suas atividades. 
Assim, pode-se pensar que o sucesso competitivo será dado pelas empresas que, além de buscar a otimização dos seus processos internos e externos já historicamente gerenciados e até certo ponto bem controlados, ataquem aquelas atividades ou fatores não considerados, no passado, como de importância estratégica (como é o caso das atividades logísticas, como dito anteriormente neste mesmo item) e que consigam reverter obstáculos econômicos de mercado em vantagem competitiva. Porter (1991) classificou vários destes obstáculos econômicos, porém, cabe mencionar a importância dada a duas dessas questões: Custos de Transporte e de Armazenamento e Canais de Distribuição Estabelecidos. Aqui, evidencia-se a preocupação que se deve ter com a concorrência global em mercados nacionais que solicitam produtos diferentes ou que, em cada mercado, existam diferentes níveis de expectativa sobre um mesmo produto, assim como a necessidade de ter acesso aos canais de distribuição em cada mercado para coibir essa mesma concorrência global.

Também com base nesses tipos de obstáculos é que as estratégias logísticas devem ser traçadas, de forma a tornar os produtos ou serviços logísticos cada vez mais competitivos ou atraentes mercadologicamente.

Depois de contextualizar a competitividade como fator de diferenciação de mercado e de vantagem empresarial, é importante dizer que o que hoje se conhece por atividade logística, operador logístico e, porque não, a própria definição de logística mudou no transcorrer dos anos, adequando-se às expectativas de cada época e definindo o perfil do que atualmente se conhece como logística empresarial, logística industrial, Supply Chain, etc.

\section{Metodologia}

Para os sistemas logísticos em geral, define-se um conjunto de atributo relacionado com variáveis diversas, formando o que se chama de nível de serviço, que é constituído pelos seguintes fatores principais (Alvarenga e Novaes, 2000, p. 90): 
- Prazo de entrega: medido pelo seu valor médio e pelo desvio médio (esse último serve para aferir a confiabilidade ou oscilação em torno da média); LEAD-TIME = Tempo de transporte + Tempo de produção $(\mathrm{PCP})+$ Tempo burocrático.

- Grau de avarias e defeitos: serve para aferir, em termos relativos (porcentagem), o aspecto integridade da carga.

- Reclamações de forma geral: dificuldade do cliente em se comunicar com a empresa, falta de follow up dos problemas para correção, mau tratamento por parte dos motoristas e ajudantes, etc.

Da mesma maneira, buscar-se-á analisar os atrasos na viagem, ocasionados por variações nos tempos de viagem, consolidação das cargas, quebra do veículo, condições adversas do tempo, paralisações e greves e por razões variadas. Outros fatores que serão analisados referem-se às oscilações nos prazos de entrega (relacionados com deficiências nas operações do depósito, armazém ou centro de distribuição), políticas de estoque, avarias na carga e descarga (utilização de veículos adequados, unitização da carga) e necessidade de equipamentos especiais para carga e descarga (moegas, caminhões basculantes, etc.).

Pode-se resumir enfatizando que o objetivo é o deslocamento de bens de um ponto para outro da rede logística, respeitando as restrições de integridade da carga e de confiabilidade (prazos), além da preocupação com a qualidade dos serviços de transporte, decorrente da necessidade de reduzir custos de estoques, pressões para reduzir prazos de entrega (exigência do mercado, concorrência), diversificação da produção, entre outros fatores.

Camargo (2000, p. 38) enumerou os principais atributos que são considerados na movimentação de carga: 
Quadro 1 - Principais atributos da movimentação de carga

\begin{tabular}{|ll|}
\hline - & $\begin{array}{l}\text { Acessibilidade ao sistema: facilidade de acesso ao sistema de } \\
\text { transporte a ser utilizado. }\end{array}$ \\
\hline - & $\begin{array}{l}\text { Confiabilidade no transporte: confiança que o sistema de } \\
\text { transporte transmite ao usuário: entrega de bens isenta de atrasos, } \\
\text { perdas e danos. }\end{array}$ \\
\hline - & $\begin{array}{l}\text { Cumprimento de prazo: cumprimento dos prazos estabelecidos } \\
\text { entre a expedição na origem e a recepção no destino. }\end{array}$ \\
\hline - & $\begin{array}{l}\text { Flexibilidade de percurso: facilidade de interligação com o mesmo } \\
\text { sistema ou com outros sistemas de transporte. }\end{array}$ \\
\hline - & $\begin{array}{l}\text { Custos de transporte: valor total do frete (não apenas os da } \\
\text { viagem, mas também com terminais, armazenagens, transbordo e } \\
\text { carga/descarga). }\end{array}$ \\
\hline - & $\begin{array}{l}\text { Rapidez de transporte: tempo consumido entre a operação de } \\
\text { carga na origem e descarga no destino. }\end{array}$ \\
\hline - & $\begin{array}{l}\text { Segurança de transporte: preservação da mercadoria, evitando } \\
\text { falhas e avarias. }\end{array}$ \\
\hline - & $\begin{array}{l}\text { Tempo para início do transporte: tempo despendido entre a } \\
\text { contratação do transporte e a retirada do produto na origem. }\end{array}$ \\
\hline
\end{tabular}

Fonte: Camargo, 2000.

Com vistas no atendimento dos objetivos do trabalho, foi feita a aplicação de questionário enviado por e-mail (de agosto a outubro de 2003), ocasião em que as empresas embarcadoras, que são as empresas demandantes do serviço de transporte, responderam às perguntas referentes aos serviços de terceirização de seus serviços de transporte, bem como formas de avaliação das prestações de serviço de transporte realizados, formais e informais. O questionário foi aplicado a um total de seis empresas, quais sejam, Sadia S/A, Coinbra S/A, Cargill S/A, I. Riedi \& Cia Ltda, Coamo Agroindustrial Cooperativa e C-Vale Agroindustrial Cooperativa. O questionário é constituído de um total de 15 questões abertas e uma fechada.

Para aplicação do questionário anexo, utilizou-se a amostragem por acessibilidade não-probabilística, tendo em vista a utilização de elementos 
que se têm acesso, admitindo-se que estes possam, de alguma forma, representar o universo (Gil, 1991, p. 83).

A tabulação e a análise das respostas traçaram um perfil mercadológico buscado pela pesquisa, a fim de se identificar um padrão para o mercado logístico de operadores.

\section{Resultados e discussão}

As empresas entrevistas nesta pesquisa atuam no ramo agroindustrial, com atividades em todo o território nacional. A Tabela 2 mostra as principais características das empresas entrevistadas.

Tabela 2 - Principais características das empresas entrevistadas

\begin{tabular}{c|c|c|c}
\hline Empresa & \multicolumn{2}{|c|}{$\begin{array}{c}\text { Volume de Comercialização (t/ano) } \\
\text { Soja }\end{array}$} & $\begin{array}{c}\text { Capacidade de } \\
\text { Milho }\end{array}$ \\
\hline A & 2.200 .000 & 4.700 .000 & 2.000 .000 \\
\hline B & 3.500 .000 & 1.800 .000 & 2.400 .000 \\
\hline C & 10.000 .000 & 4.500 .000 & 3.000 .000 \\
\hline D & 600.000 & 2.500 .000 & 600.000 \\
\hline E & 950.000 & 630.000 & 800.000 \\
\hline F & Não informou & Não informou & 222.000 \\
\hline Total & $\mathbf{1 7 . 2 5 0 . 0 0 0}$ & $\mathbf{1 4 . 1 3 0 . 0 0 0}$ & $\mathbf{9 . 0 2 2 . 0 0 0}$ \\
\hline
\end{tabular}

Fonte: Dados de pesquisa.

A Figura 1 mostra que o serviço de transporte é o de maior destaque entre os serviços contratados pelas empresas embarcadoras. Visualizase, também, o mercado que existe para um operador logístico, envolvendo as demais atividades, como, por exemplo, a armazenagem aliada a uma gestão integrada dos estoques, bem como a tecnologia de informação necessária ao monitoramento e à segurança das operações logísticas aos contratantes. Richetti e Caixeta Filho (2003, p.7) mostraram que os serviços de transporte, armazenagem e controle de estoques, respecti- 
vamente com 100, 89 e 79 percentuais, são atividades desenvolvidas pelos operadores logísticos existentes no mercado.

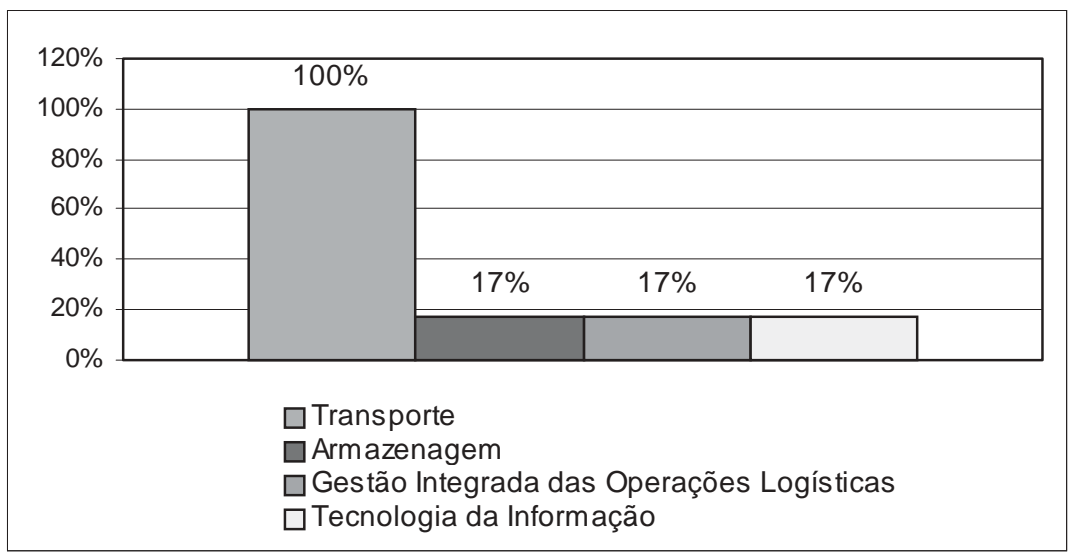

Fonte: Dados de pesquisa.

Figura 1 - Serviços logísticos contratados pelas empresas embarcadoras.

Quanto à gestão do transporte dentro das operações logísticas, 88,33\% das empresas entrevistadas possuem atividade de transporte de grãos terceirizada, enquanto 22,50\% dos entrevistados possuem frota própria para o transporte. Porém, esta frota própria é suficiente apenas para o transporte de pequena parcela do volume comercializado, segundo Araújo e Martins (2002). Da mesma forma, 30\% das empresas entrevistadas terceirizam o serviço de transporte de farelo; e apenas 9,17\% possuem frota própria; e 50\% não realizam atividade com farelo.

Na Figura 2, observa-se o conceito de operador logístico na concepção dos embarcadores de commodities agrícolas. Verifica-se que $33 \%$ das empresas entrevistadas esperam que o operador logístico preste apenas serviço de transporte, enquanto $67 \%$ esperam que transporte, armazenagem e controle de estoques sejam atividades básicas prestadas pelos operadores logísticos. Em comparação, segundo Richetti e Caixeta Filho (2003, p. 8), verifica-se que há similaridade muito grande em relação aos serviços que empresas contratantes esperam que sejam prestados pelos operadores logísticos, sendo que $84 \%$ das empresas entrevistadas 
pelos autores esperam que, como atividade básica, sejam prestados os serviços de transporte, armazenagem e controle de estoques.

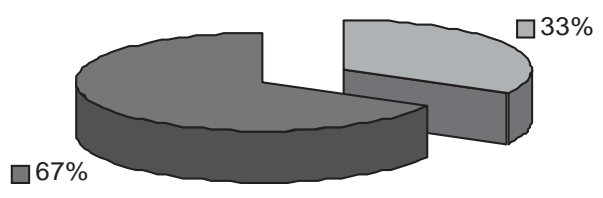

$\square$ Apenas serviços de transporte $\square$ Transporte, armazenagem e controle de estoques (no mínimo)

Fonte: Dados de pesquisa.

Figura 2 - Serviços que configuram um operador logístico, na concepção dos Embarcadores.

Quando questionados sobre uma relação contratual formal entre a empresa e o ofertante do serviço, 83\% das empresas informaram haver contratação formal, enquanto somente uma empresa (17\%) respondeu haver poucas contratações formais, tendo em vista a contratação de empresas transportadoras já conhecidas. Nesse caso, a maioria das empresas, ou ainda em $66 \%$ dos casos, avalia os transportadores no ato da contratação da empresa, periodicamente, de acordo com os serviços prestados, sendo considerados a idoneidade, a seriedade no tratamento de problemas e o cumprimento de contrato suas principais características. Das demais empresas, $17 \%$ contratam o serviço por terceiros e avalia a qualidade dos serviços prestados e $17 \%$ contratam seguros p/ acobertar o produto, procurando, dessa forma, diminuir seus riscos, avaliando também os serviços prestados pelos "parceiros".

Araújo e Martins (2002, p. 8), em análise sobre contratação formal, verificaram que "em nenhuma das empresas pesquisadas existe um contrato formal entre o embarcador de grãos e a transportadora; mas os empresários foram unânimes em afirmar que, apesar desta relação informal, buscam-se mecanismos para minimizar os riscos deste merca- 
do". As especificações exigidas pela empresa, em relação aos caminhões, são feitas em $33 \%$ dos casos, sob forma de avaliação de cadastro, enquanto $67 \%$ fazem um chek list das especificações exigidas pela empresa no ato da contratação das transportadoras, mostrando que exigem de seus prestadores de serviço uma frota em boas condições para o transporte de commodities, procurando minimizar os riscos com sinistros e roubos por meio da contratação de seguros. Além disto, 50\% das empresas avaliam como risco o não-cumprimento dos contratos de transporte celebrado com as transportadoras. Da mesma forma, 17\% relacionaram também como risco, no caso de transporte férreo, a demora da entrega do produto, o que ocasiona possíveis deteriorizações destes.

Os atributos valorizados e considerados determinantes por $50 \%$ dos entrevistados, foram a pontualidade e os volumes de entrega acordados. Tem-se, como ação, uma escolha rigorosa das transportadoras, visto que, sempre procuram contratar transportadoras idôneas. Já no caso de transporte de cargas frigoríficas, analisado por Araújo e Martins (2002, p. 12), as exigências são maiores, como, por exemplo, a especificidade dos ativos físicos que não são desprezíveis, dada a necessidade de conservação da qualidade dos produtos transportados.

A freqüência das transações efetuadas com as transportadoras, apresentada por $67 \%$ dos entrevistas, é diária/semanal, enquanto $33 \%$ utilizam o serviço de forma sazonal, ou seja, em períodos de safra, as contratações são diárias e, nos demais meses do ano, tornam-se quinzenais, dependendo muito do mercado de commodities onde o produtor aumenta ou retrai a venda dos produtos. Araújo e Martins (2002, p. 10) verificaram que a freqüência com a qual ocorre a transação no transporte de grãos e cargas frigorificadas deve ser considerada como constante em todas as empresas, podendo haver necessidade de mais ou menos caminhões, mas o número de transportadores contratados tende a ser estável. Já Camargo (2000, p. 56) analisou que a freqüência de oferta de equipamentos para transporte, caminhões ou vagões é tão ou mais importante que o preço, tendo em vista que aumentar o preço do frete não solucionará a falta de veículos em períodos de safra. 
Nesse caso, a alta frequiência auxilia na redução da possibilidade de comportamento oportunista por parte dos agentes no mercado. Esse resultado também sugere avaliação mais informal e menos rigorosa por parte do embarcador, pois, nesse mercado, sabe-se, sobram caminhões.

Na avaliação das empresas embarcadoras, o mercado de grãos é um espaço em que maior parte do volume é transportado, majoritariamente, por via rodoviária, o que agrega altos custos a commodity. Os transportes férreos e fluvial deveriam ser mais utilizados, segundo os entrevistados, tendo em vista que oferecem preços de transporte mais competitivos. No entanto, não existe infra-estrutura suficiente para atender à expansão da demanda e da produção do Brasil. Nesse sentido, as empresas esperam que haja uma interação cada vez maior entre os modais de transporte, visando tornar o país mais competitivo mundialmente.

Como analogia, as empresas entrevistadas transportam, em média, 11\% de suas commodities pelas ferrovias, fazendo uso destas pelo custo inferior ao transporte rodoviário. Apenas uma das empresas não utiliza o transporte ferroviário, tendo em vista que suas fábricas não têm proximidade com as linhas férreas, sendo o transbordo considerado de custo elevado, o que inviabiliza seu uso.

A empresa operadora da linha ferroviária do Paraná - Ferropar transporta, em média, 1.800.000 /ano, com vagões de capacidade média de 50 toneladas e uma média de 33 vagões $\mathrm{p} /$ trem, com percurso que leva de 4 a 5 dias. Segundo 33\% das empresas entrevistadas, o uso do transporte ferroviário só não é devido à pouca oferta de vagões e à demora para a chegada no destino. A Ferropar, por sua vez, espera aumentar a oferta de vagões para a safra 2003/2004, de acordo com investimentos previstos pela empresa, bem como diminuir o tempo de chegada das commodities aos portos.

Uma avaliação qualitativa dos serviços prestados pelos transportadores é efetuada por todas as empresas contratantes. No entanto, apenas uma empresa efetua uma verificação diária dos serviços prestados por meio da observância das cadências contratadas e da agilidade e transparência 
no atendimento de cotações. As demais empresas afirmam ter uma avaliação dinâmica de todos os serviços contratados, porém não possuem este modelo formalizado.

As Figuras 3 a 8 mostram como as empresas contratantes de serviços de transporte avaliam a qualidade dos serviços prestados.

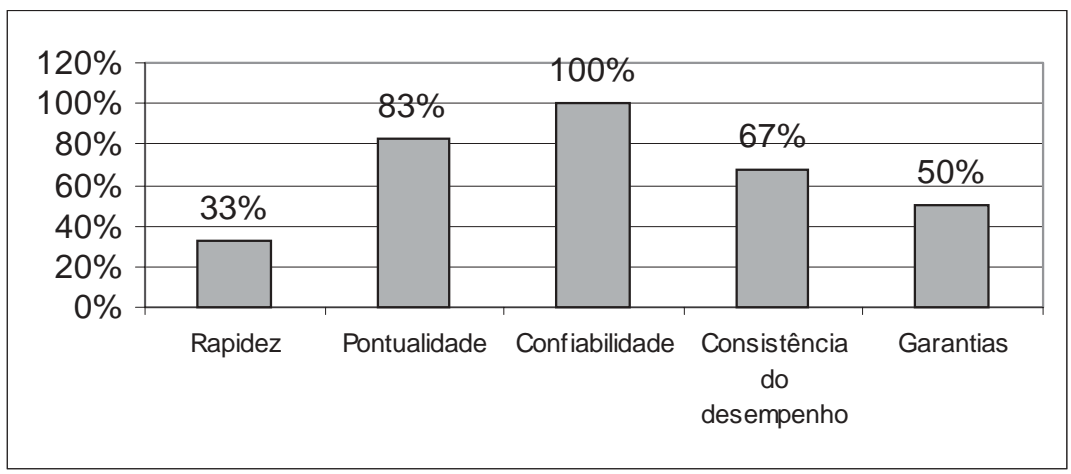

Fonte: Dados de pesquisa.

Figura 3 - Atributos dos serviços de coleta e entrega, na opinião dos embarcadores.

Na Figura 3, observa-se a importância que é atribuída a todos os itens, o que reforça pontos como confiabilidade, pontualidade e consistência do desempenho presentes em mais de $50 \%$ dos embarcadores, não tendo importância os fretes realizados porta-a-porta. Já Camargo (2000, p. 56) verificou que a acessibilidade foi o último item referenciado pelo do grupo pesquisado, com um mínimo de influência, tendo em vista que o único acesso ferroviário está localizado na cidade de Cascavel, no oeste do Paraná e, no caso do transporte rodoviário, a preocupação é nula.

Quando se trata de avaliar os prestadores de serviço por sua cobertura geográfica (Figura 4), percebe-se que a grande maioria leva em consideração a abrangência com que os contratados possam prestar os serviços, o que demonstra a busca da competividade das empresas na aquisição de commodities com preços inferiores. Araújo e Martins (2002, p. 8) verificaram que a proximidade cria um certo "elo de fidelidade", 
podendo evitar comportamento oportunístico, que é muito comum, na visão do empresário, mostrando que a proximidade pode ser benéfica para o relacionamento entre as empresas, haja vista que proporciona melhor acompanhamento dos serviços prestados.

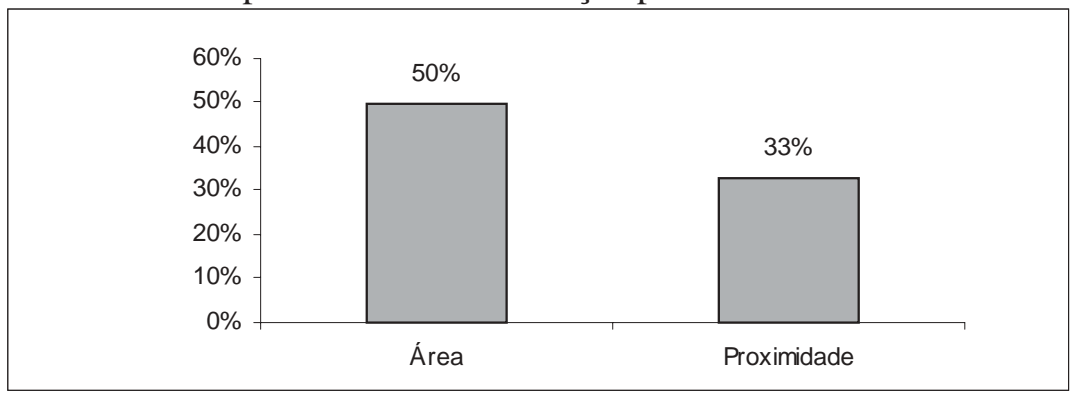

Fonte: Dados de pesquisa.

Figura 4 - Cobertura geográfica a ser atendida, na opinião das empresas embarcadoras do serviço de transporte.

A Figura 5 avalia os tipos de serviços relevantes na avaliação dos contratantes, dando destaque aos serviços de classificação de cereais, gerenciamento intermodal (já que aproximadamente $11 \%$ das empresas utilizam transporte ferroviário) e ainda Just in time.

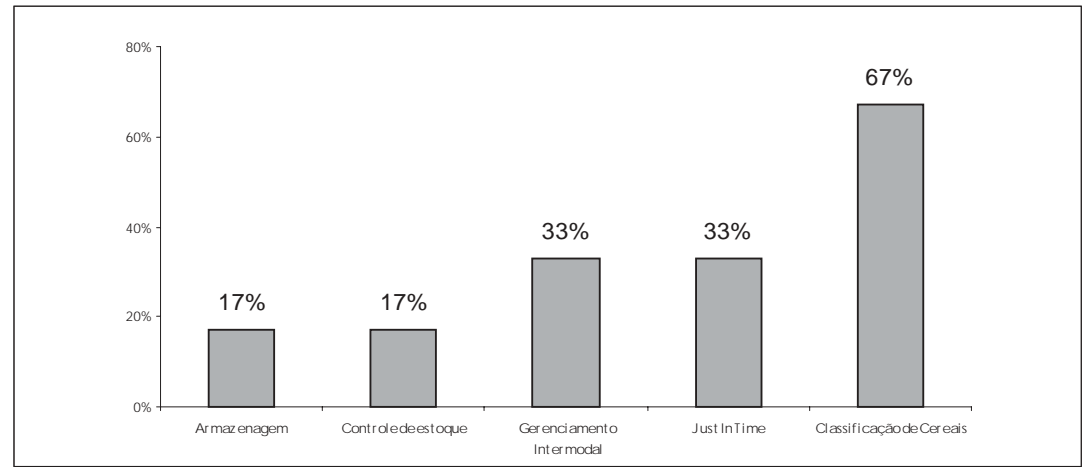

Fonte: Dados de pesquisa.

Figura 5 - Serviços que deveriam ser oferecidos pelo operador logístico, na opinião das empresas embarcadoras. 
Na Figura 6, é mostrada a importância atribuída ao uso de equipamentos especiais para rastreabilidade da carga. Percebe-se que a maior parte das empresas contratantes não leva muito em consideração o uso desse tipo de equipamento, visto que apenas uma empresa afirmou utilizar-se de rastreamento por satélite para a frota própria, e outra afirmou que utiliza roteirizadores para frota própria e terceirizada no transporte. As demais empresas afirmaram não utilizar nenhuma forma de rastreabilidade das cargas.

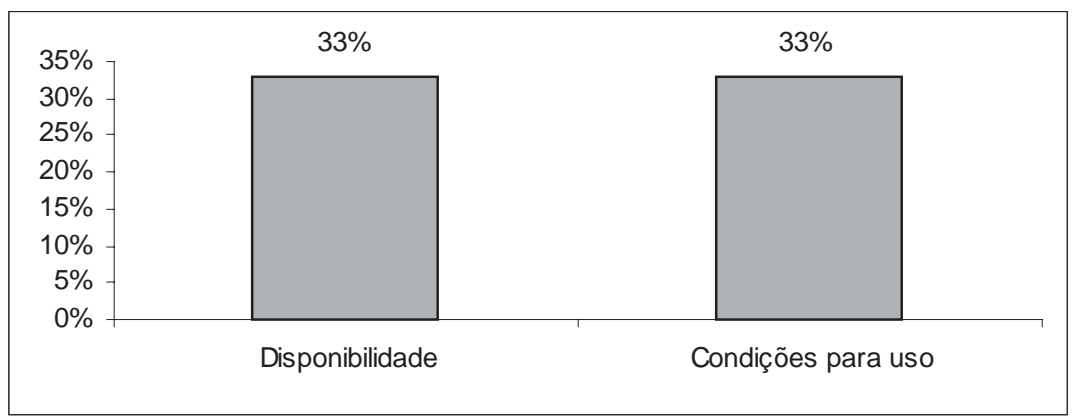

Fonte: Dados de pesquisa.

Figura 6 - Importância do uso de equipamentos de rastreabilidade da carga, na opinião das empresas embarcadoras do serviço de transporte.

Já nas Figuras 7 e 8, em contraposição, observa-se a grande importância que se atribui à flexibilidade nos atendimentos emergenciais, carregamentos especiais, tratamento de problemas/anomalias e, principalmente, na flexibilidade de negociações de variações na prestação dos serviços. 


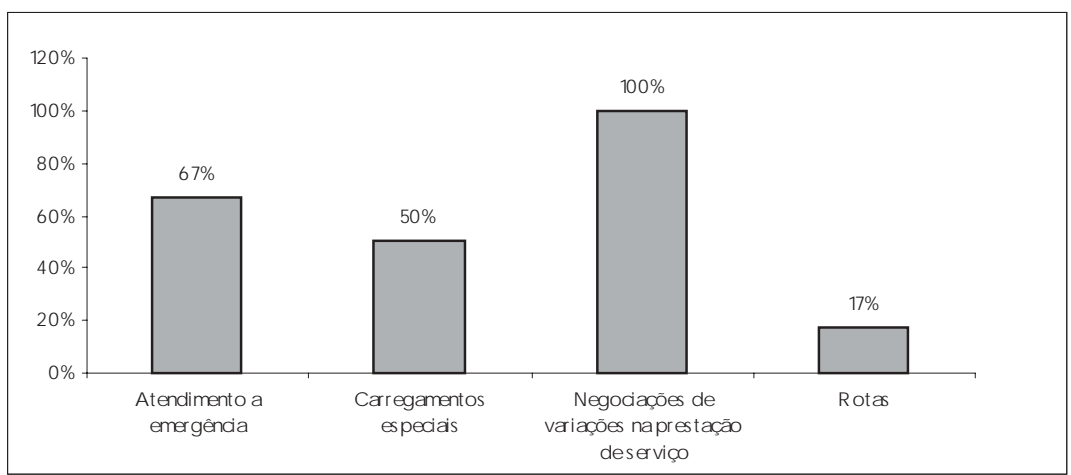

Fonte: Dados de pesquisa.

Figura 7 - Importância atribuída à flexibilidade de negociação com as empresas prestadoras de serviço de transporte.

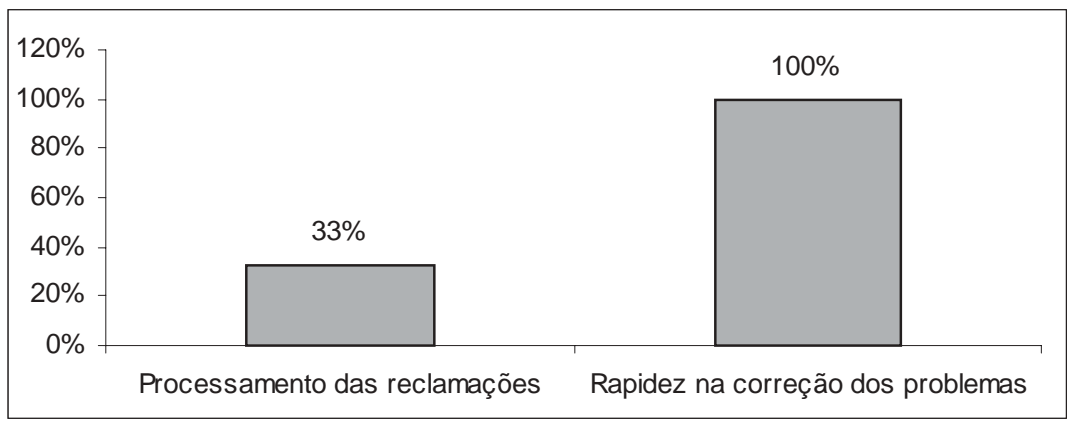

Fonte: Dados de pesquisa.

Figura 8 - Importância atribuída ao atendimento de reclamações, na opinião das empresas embarcadoras do serviço de transporte.

Na Figura 9, visualiza-se a nota média atribuída pelos entrevistados aos atributos avaliados, considerando-se a qualidade dos serviços prestados. Observa-se que a flexibilidade, seguida da reação às reclamações e dos serviços de coleta e entrega, é o atributo mais observado pelas empresas embarcadoras do serviço de transporte. 


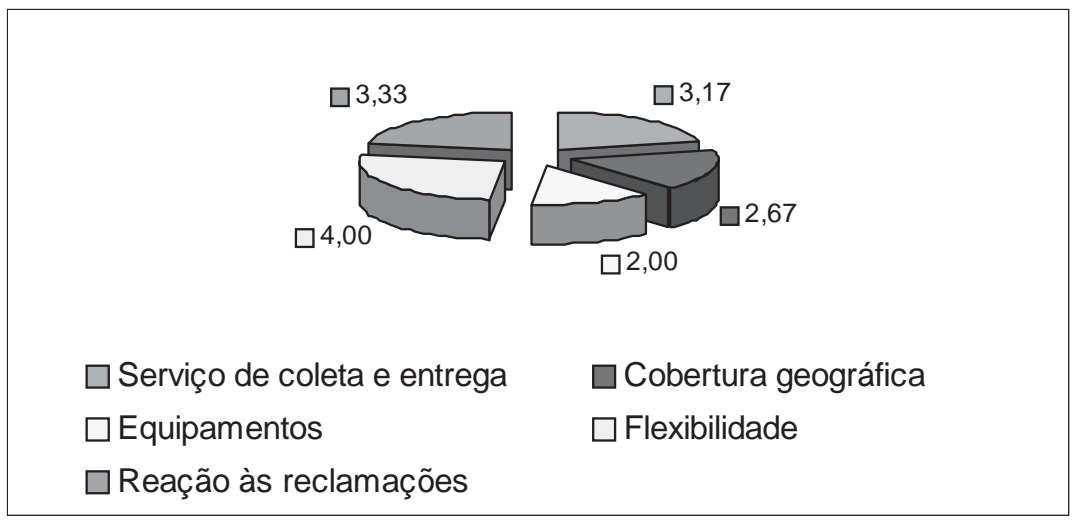

Fonte: Dados de pesquisa.

Figura 9 - Notas atribuídas pelas empresas entrevistadas à importância dos atributos avaliados.

A Figura 10 permite visualizar e traçar um comparativo com o trabalho de Richetti e Caixeta Filho (2003, p. 10), em que os autores se referem ao fato de $67 \%$ das empresas responderam que, ao se contratar um serviço de operador logístico, elas passam a ter um tempo maior de dedicação ao seu próprio negócio. De forma similar, este trabalho mostra que o mesmo percentual é atribuído pelas empresas entrevistadas ao tempo maior dedicado à empresa. No entanto, vale ressaltar que o mesmo percentual é esperado pelas contratantes, com vistas em melhorar a relação com seus clientes e ainda reduzir custos. Mas o que neste trabalho é apresentado com maior ênfase pelos contratantes é a precisão nas datas de entrega, a que é esperada na contratação de um operador logístico para commodities, segundo um total de $83 \%$ das empresas entrevistadas. 


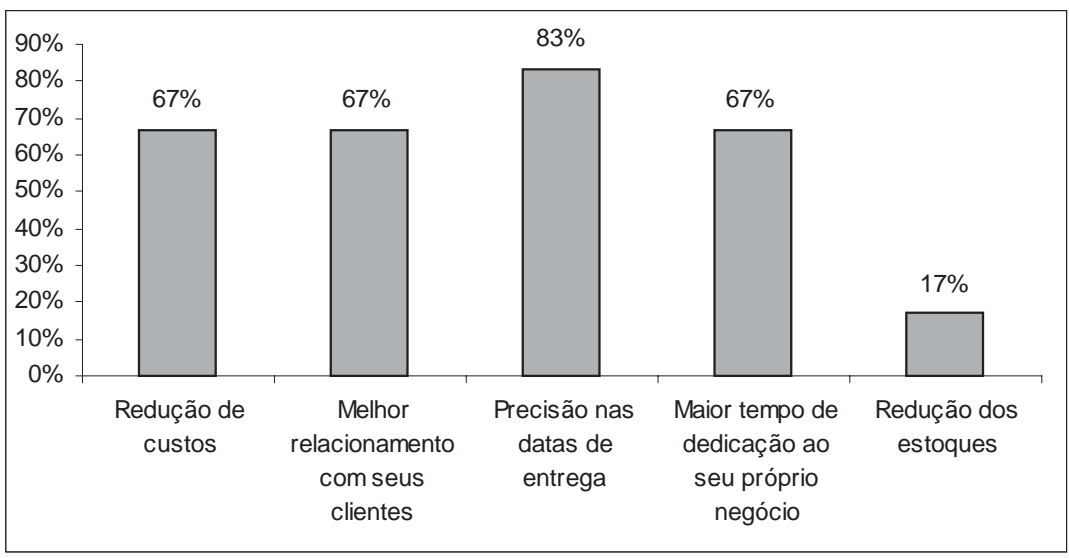

Fonte: Dados de pesquisa.

Figura 10 - Benefícios trazidos às empresas por contratar um operador logístico (na opinião das empresas contratantes).

\section{Considerações finais}

O objetivo deste estudo foi identificar os atributos valorizados na contratação de operações logísticas pelos agentes na tomada de decisões no mercado de commodities agrícolas, com interesse específico na avaliação dos principais critérios para contratação e avaliação de um operador logístico, assim como verificar a existência, ou não, de um padrão adotado pelos contratantes nesta avaliação, bem como na avaliação comparativa do nível de exigência dos serviços contratados.

A utilização de operadores logísticos pode ser entendida a partir do aperto nas margens de operação, que tem forçado as empresas a tomarem decisões sobre a viabilidade de as empresas otimizarem todas as operações ou buscarem a solução otimizadora em prestadores de serviço . Nesse sentido, as atividades logísticas também estão contempladas no rol de operações terceirizadas. 
Assim, este estudo levantou as práticas do mercado de commodities sobre a existência de modelos gerenciais de avaliação, com maior interesse nos principais atributos valorizados pelo mercado. As informações foram obtidas de questionários encaminhados aos responsáveis pela comercialização de empresas que comercializam um volume significativo de grãos, respectivamente, 17,25 e 14,13 milhões de t de soja e milho.

Como síntese dos resultados, constata-se que o transporte é a principal e, às vezes única na visão logística do setor. A maior demanda de operações logísticas recai sobre o transporte e, além disso, todas as empresas demandam essas operações, mesmo as que têm frota própria. Na visão dos embarcadores de commodities agrícolas, transporte e logística ainda são termos vistos como sinônimos. Essa visão pode limitar bastante o horizonte de terceirização de atividades, bem como o nível de exigência com o serviço prestado.

Mesmo que não-sistemática, a avaliação da qualidade do serviço prestado é feita pelo embarcador. A frequiência das operações faz com que seja facilitada a tarefa de avaliação do desempenho dos prestadores de serviço. Há que se considerar, nesse contexto, que a avaliação de desempenho não se refere a qualquer sistema mais rígido de controle além do cumprimento da pontualidade e dos volumes, mesmo porque o caráter sazonal, muitas vezes, coloca a pressa acima do atributo "perfeição". O ofertante é pressionado a não agir de forma oportunista, dado o excesso de oferta de veículos no mercado.

A elevação dos serviços prestados está sinalizada pelos embarcadores na direção da classificação de cereais, do gerenciamento intermodal e do Just in time. Entretanto, em aparente contradição, os embarcadores não priorizam soluções logísticas que possam ser viabilizadas com incorporação de equipamentos da tecnologia da informação que permitam maior transparência no processo logístico, como o rastreamento, por exemplo. 
Conforme avaliação dos embarcadores, os itens mais importantes no serviço prestado são, na seqüência, flexibilidade, reação às reclamações e serviço de transporte propriamente dito. Os embarcadores não percebem, com clareza, o potencial de melhorias na logística da empresa, ao estabelecerem parcerias com os operadores logísticos, além da maior agilidade.

Em suma, pode-se concluir que há rigidez na gestão logística da comercialização de commodities agrícolas, visto que os embarcadores, estrategicamente ou pela própria dinâmica do mercado, tendem a "comoditizar" os serviços logísticos, não avaliando o potencial de ganho de terceirização de operações além do transporte, o que faz com que, para esses negócios, transporte e logística sejam sinônimos.

\section{Referências Bibliográficas}

ALVARENGA, Antonio Carlos; NOVAES, Antonio Galvão N. Logística Aplicada Suprimento e Distribuição Física. 3 ed. São Paulo: Edgard Blücher, 2000.

ALVES, Eduardo Sampaio. Sistemas logísticos integrados: um quadro de referência. 2000. 109 f. Dissertação (Mestrado em Engenharia de Produção) - Universidade Federal de Santa Catarina, Florianópolis.

ARAÚJO, M. P.; MARTINS, R. S. Logística de transporte de cargas do agronegócio brasileiro: evidências para uma interpretação à luz da teoria dos custos de transação In: IV CONGRESSO BRASILEIRO DE ECONOMIA E SOCIOLOGIA RURAL, 2002, Passo Fundo. Anais. , 2002.

BOYSON, Sandor; et al. Managing Effective Third-Party Logistics Relationships: What Does It Take? Journal of Business Logistics, vol. 20, n. 1, p.23-35. 1999. Disponível em: 〈http://www.cel.coppead.br〉. Acesso em: 19 Jun. 2003. 
CAMARGO, Odair. Identificação dos principais atributos considerados no transporte de cargas: estudo de caso no oeste paranaense. 2000. 95 f. Dissertação (Mestrado em Engenharia de Produção) - Universidade Federal de Santa Catarina, Florianópolis.

COLLI, Paulo. Um modelo de avaliação de desempenho da distribuição física. 2001. 129 f. Dissertação (Mestrado em Engenharia de Produção) - Universidade Federal de Santa Catarina, Florianópolis.

CSILlaG, João Mario. Análise do valor: engenharia do valor, gerenciamento do valor, redução de custos, racionalização administrativa. 4 ed. São Paulo: Atlas, 1995.

DORNIER, Philippe-Pierre; et al. Logística e operações globais: textos e casos. Philippe-Pierre Dornier, Ricardo Ernst, Michael Fender e Panos Kouvelis. São Paulo: Atlas, 2000. 721 p.

GIL, Antonio Carlos. Técnicas de Pesquisa em Economia. 2 ed. São Paulo: Atlas, 1991. 195 p.

KAPLAN, Robert S. NORTON, David P. A estratégia em ação: balanced scorecard. Rio de Janeiro: Campus, 1997. 334 p.

NOVAES, Antonio Galvão. Logística e gerenciamento da cadeia de distribuição: estratégia, operação e avaliação. 1 ed. Rio de Janeiro: Campus, 2001. 409 p.

PORTER, Michael E. Estratégia competitiva: técnicas para análise de indústrias e da concorrência. 7 ed. Rio de Janeiro: Campus, 1991. $362 \mathrm{p}$.

RAZZOLINI FILHO, Edelvino. Avaliação do desempenho logístico de fornecedores de medicamentos: um estudo de caso nos hospitais paranaenses. 2000. 202 f. Dissertação (Mestrado em Engenharia de Produção) - Universidade Federal de Santa Catarina, Florianópolis. 
RICHETTI, Priscila; CAIXETA-FILHO, J. V. Identificação dos principais critérios para contratação e avaliação de operadores logísticos. In: IV CONGRESSO BRASILEIRO DE ECONOMIA E SOCIOLOGIA RURAL, 2003, Juiz de Fora. Anais. 2003. 